\title{
Synthesis and characterization of tungsten-incorporated mesoporous molecular sieve MCM-48 by one step
}

\author{
Derun Hua • Shengli Chen • Guimei Yuan • \\ Yulong Wang
}

Published online: 30 November 2010

(C) The Author(s) 2010. This article is published with open access at Springerlink.com

\begin{abstract}
Tungsten-substituted mesoporous MCM-48 materials are successfully synthesized at $393 \mathrm{~K}$ by a onestep co-condensation sol-gel method. The prepared samples with different $\mathrm{Si} / \mathrm{W}$ ratios are characterized by X-ray diffraction (XRD), nitrogen adsorption, high-resolution transmission electron microscopy (HRTEM), diffuse reflectance UV-visible spectroscopy and FT-IR, and the results indicate the presence and good dispersion of tungsten species inside the silica pores, the $\mathrm{Si} / \mathrm{W}$ ratio is controlled above 28 . When the $\mathrm{Si} / \mathrm{W}$ ratio is less than 28 , though no bulk tungsten is detected outside the MCM-48 mesoporous silica, the pore structure order becomes worse.
\end{abstract}

Keywords Mesoporous materials · W-MCM-48 ·

Tungsten

\section{Introduction}

In 1992, researchers at Mobil Corporation reported a series of ordered mesoporous silicates, which were synthesized by the self-assembly of surfactants and inorganic species [1]. M41S were generally referred to MCM-41 and MCM48, and possessed well-defined pore structures. MCM-41 possessed a large specific surface area, a hexagonal array, and uniform mesopore channels. MCM-48 had a cubic pore system indexed in the space group Ia3d, and possessed a bicontinuous structure centered on the gyroid minimal surface [2] that divided available pore space into two

D. Hua $\cdot$ S. Chen $(\bowtie) \cdot$ G. Yuan $\cdot$ Y. Wang

State Key Laboratory of Heavy Oil Processing, College of Chemical Science and Engineering, China University of Petroleum, 102249 Beijing, People's Republic of China e-mail: slchen@cup.edu.cn nonintersecting subvolumes [3, 4] The discovery of mesoporous materials offered an opportunity for catalyst supports.

Recently, MCM-48 indexed to an Ia3d unit cell [5], had attracted much attention because of its unique threedimensional pore structure that was more desirable than MCM-41 for industrial applications. Since it's highly interwoven and branched structure provided many places MCM-48 could avoid pore blockage caused by reactant molecules. However, pure siliceous MCM-48 limited its practical application especially in catalysis owing to be lack of active sites in the wall. Hence, it was of great importance to incorporate heteroatom into the walls of these mesoporous silica materials.

The incorporation of transition-metal elements such as $\mathrm{Al}, \mathrm{Ga}, \mathrm{Mn}, \mathrm{Cr}, \mathrm{Zr}$, and $\mathrm{V}$ into the amorphous silica walls was mandatory for the formation of catalytic active sites in mesoporous molecular sieves. Many efforts had focused on MCM-41 [6-8] and SBA-15 [9, 10]. And a few of works had aimed at MCM-48 [11-16]. In addition, there were materials about tungsten incorporated, such as W-HMS [17], W-SBA-15 [18, 19] and W-MCM-41 [20-22], which were synthesized easily. However, little attention was paid to the synthesis and characterization of tungsten incorporated MCM-48 [23, 24], the MCM-48 phase was often an intermediate during the transformation from a hexagonal phase to a lamellar phase, other ion added destroyed easily an intermediate, so metal incorporated MCM-48 materials were more difficult to synthesize than to synthesize MCM-48. Though it was difficult to synthesize tungstencontaining MCM-48, catalytic performance of tungstencontaining MCM-48 was better than $\mathrm{WO}_{3} / \mathrm{MCM}-48$ because $\mathrm{WO}_{3}$ species were highly dispersed into the lattice of the bulk. Yang et al. [23] synthesized W-MCM-48 by two steps and applied W-MCM-48 to oxidation of CPE. 
Morey et al. [25] used $\mathrm{W}\left(\mathrm{OC}_{2} \mathrm{H}_{5}\right)_{5}$ as tungsten source to synthesize W-MCM-48 and investigated perspectives on catalytic peroxide activation. Recently, metal incorporated silica materials attract attentions in the fields, such as metathesis [26], Absorbent [27]. So formation of catalytic active sites in mesoporous molecular sieves is important work, but the methods reported in previous literatures were complicated. Firstly hydrothermal condition kept in stainless steel autoclave for $72 \mathrm{~h}$ and $\mathrm{pH}$ was adjusted by hydrochloric acid, then hydrothermal condition kept $24 \mathrm{~h}$. So we take attempt to synthesize W-MCM-48 by one step without adjusting $\mathrm{pH}$ and short synthesizing time.

Here, this paper reports tungsten incorporated into mesoporous silica pores by one step co-condensation solgel method which improves dispersion of the tungsten species, alleviates aggregation of $\mathrm{WO}_{3}$ and strengthens interactions between tungsten species and silica. Introducing tungsten into MCM-48 materials opens new opportunities for further synthesis of tungsten oxide materials. The method used in this work is a simple and new approach for the synthesis of tungsten-containing mesoporous silica materials.

\section{Experimental Sections}

\subsection{Materials}

The reagents used in this study are tetraethylorthosilicate (TEOS) as silica source, cetyltrimethylammonium bromide (CTAB) as surfactant, sodium hydroxyl $(\mathrm{NaOH})$ as alkali source, ammonium metatungstate as tungsten source and deionized water.

\subsection{Synthesis}

The ordered mesoporous W-MCM-48 was synthesized by assembly of surfactant micelle with silicate precursors in alkali media as described in the literature [14]. The synthesis of W-MCM-48 was as follows: The molar composition of the reaction mixture is $\mathrm{SiO}_{2}$ : CTAB: $\mathrm{Na}_{2} \mathrm{O}: \mathrm{H}_{2} \mathrm{O}$ : $\mathrm{WO}_{3}=1$ : 0.55: 0.025: 60: $(0-0.05)$. $10.0 \mathrm{~g}$ of CTAB is added into $50.0 \mathrm{~g}$ of $0.5 \mathrm{M} \mathrm{NaOH}$ aqueous solution, and the solution is stirred at $318 \mathrm{~K}$ for $1 \mathrm{~h}$. Then, $10.7 \mathrm{~g}$ of TEOS and $4.0 \mathrm{~g}$ of $84 \mathrm{wt} \%$ ammonium metatungstate solution were added to the solution under vigorous stirring at $318 \mathrm{~K}$. The resulting gel is stirred for $3 \mathrm{~h}$ at $318 \mathrm{~K}$ and transferred into Teflon-lined stainless steel autoclave with polytetraflourethylene and kept in an air oven at $393 \mathrm{~K}$ for another $24 \mathrm{~h}$. Finally, the mixture is cooled down, and the solid products are collected after filtration, washed with water, dried and calcined at $823 \mathrm{~K}$ in flowing air for $5 \mathrm{~h}$.

\subsection{Characterization}

X-ray powder diffraction patterns were recorded on a Bruker D8 ADVACE diffract meter with CuKa radiation of wavelength $1.5406 \AA$ in the $2 \theta$ range of $1.5-80^{\circ}$ with scanning rate of $1^{\circ} \mathrm{min}^{-1}$. $\mathrm{N}_{2}$ adsorption-desorption isotherms at $77 \mathrm{~K}$ was recorded with a Micromeritics ASAP 2010 automatic adsorption analyzer after the catalyst samples were degassed at $523 \mathrm{~K}$ for $3 \mathrm{~h}$. The BET surface area was calculated from the desorption isotherm in the relative pressure range of $\mathrm{P} / \mathrm{P}_{0}=0.01-1.0$. The high-resolution transition electron microscope (HRTEM) images were obtained with a Tecnai G2 F20 Super-twin. The UV-Vis DRS of the catalyst samples were recorded, in the range of 200-800 $\mathrm{nm}$ against the support as reference, on a Hitachi U-4100 spectrophotometer equipped with an integration sphere diffuse reflectance attachment. The mid-infrared spectra had been collected on the Digilab FTS-3000 FT-IR spectrometer using KBr pellet technique. About $15 \mathrm{mg}$ of the sample was pressed (under a pressure of $10 \mathrm{MPa}$ ) into a self-supported wafer of $13 \mathrm{~mm}$ diameter. This pellet was used to record the infrared spectra in the range $1,300-400 \mathrm{~cm}^{-1}$.

\section{Results and Discussion}

\subsection{XRD analysis}

The quality and structural ordering of W-MCM-48 materials were evaluated by powder small angle XRD $\left(1.5^{\circ}-6^{\circ}\right)$. Figure 1 showed the small angle XRD patterns of W-MCM-48 and MCM-48. Except for $\mathrm{Si} / \mathrm{W}=20$, the two XRD reflection peaks (211) and (220)at $1.5^{\circ}-6^{\circ}$, which were indexed to Ia3d cubic structure [1], were all welldefined and in good agreement with the reported patterns of MCM-48 material in literature [28]. When the ratio of $\mathrm{Si} /$ W decreased from 93 to 28, the two diffraction peaks were still clearly observed. No significant changes were observed in the small angle XRD patterns of the W-MCM48 with different the amount of tungsten oxide, except for the change in XRD peak intensity. The intensity of small angle XRD peaks and the well resolved peaks indicated the long-range ordering of the mesoporous silica materials prepared. When ratio of $\mathrm{Si} / \mathrm{W}$ was 28 , the intensity of peaks (211) and (220) became weaker obviously than that of the MCM-48, indicating the long-range ordering of the material to be worse. When ratio of $\mathrm{Si} / \mathrm{W}$ was 20 , one peak was well-resolved, which indicated that the ordering of the synthesized materials became worse. The reason might be that a large amount of ammonium tungsten caused the $\mathrm{pH}$ value of resulting gel to decrease. 


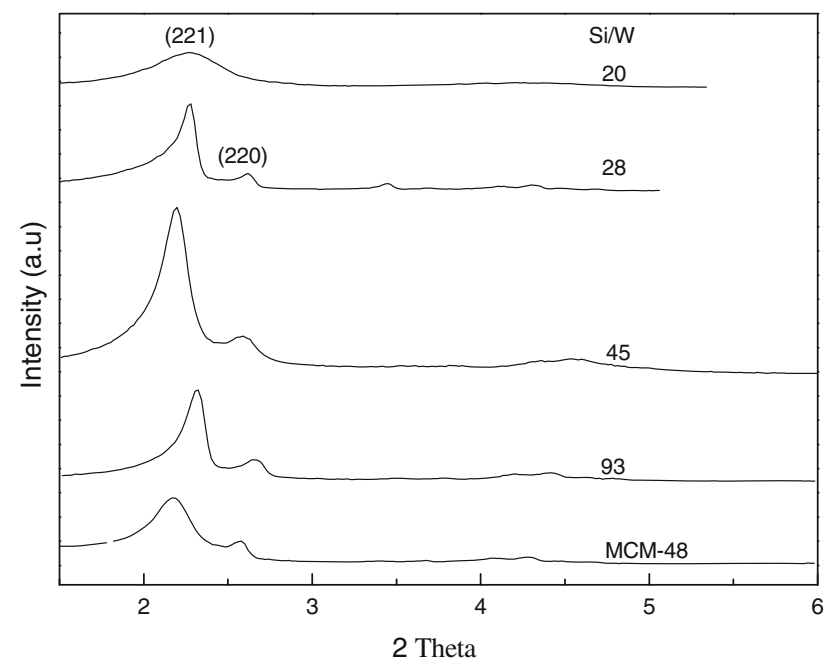

Fig. 1 Small-angle XRD patterns of MCM-48 with different Si/W ratios

The normal XRD $\left(10^{\circ}-80^{\circ}\right)$ patterns of W-MCM-48 with different $\mathrm{Si} / \mathrm{W}$ ratios were shown in Fig. 2 in order to detect the bulk $\mathrm{WO}_{3}$. No diffraction peaks of $\mathrm{WO}_{3}$ were found, the $\mathrm{WO}_{3}$ species were well dispersed into the MCM-48.

\section{$3.2 \mathrm{~N}_{2}$ adsorption analysis}

Figure 3 presents the $\mathrm{N}_{2}$ adsorption isotherm of the W-MCM-48 materials with various ratios of $\mathrm{Si} / \mathrm{W}$. Textural characteristics of W-MCM-48 samples are presented in Table 1. The isotherms of in all samples show type IV adsorption isotherms (IUPAC) belonging to typical mesoporous materials [5]. The steep increase of the $\mathrm{N}_{2}$ adsorption/desorption isotherm is observed in the relative pressures $\left(\mathrm{P} / \mathrm{P}_{\mathrm{o}}\right)$ from 0.0 to 0.3 and 0.3 to 0.7 , which is due

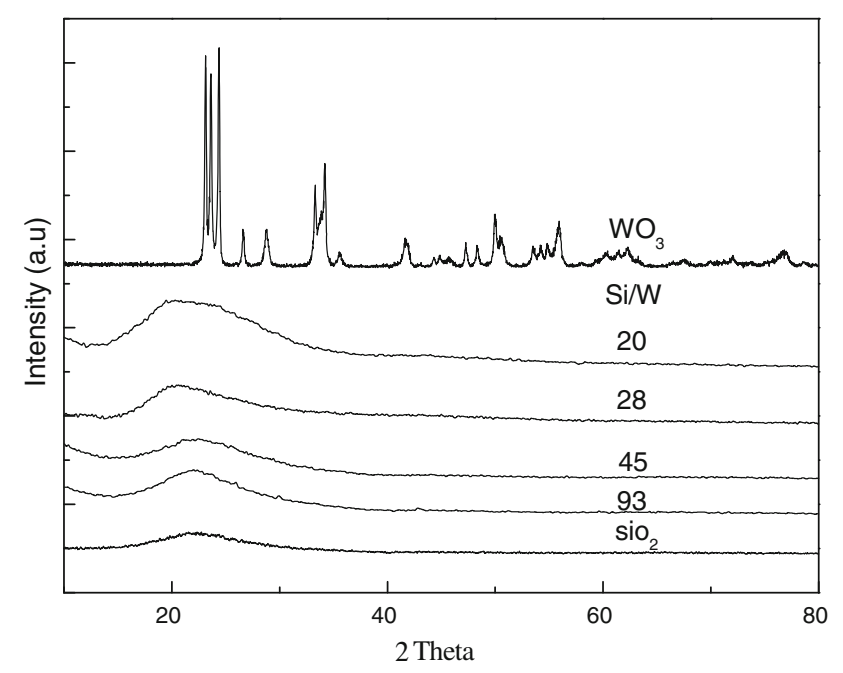

Fig. 2 XRD patterns of MCM-48 with different $\mathrm{Si} / \mathrm{W}$ ratios to the reversible capillary with the mesopores of materials. In general, for mesoporous molecular sieves, the steepness of the capillary condensation in the isotherms indicates the narrow pore size of distribution. There are two separate well-defined hysteresis loops. One of the hysteresis loops is in the region of $\mathrm{P} / \mathrm{P}_{0}=0.0-0.3$ and related to the diameter of mesopores, and the other is at $\mathrm{P} / \mathrm{P}_{0}>0.3$, which corresponds to the capillary condensation in the interparticle pores [29]. The sharp inflection point shifted toward higher relative pressure $\left(\mathrm{P} / \mathrm{P}_{0}\right)$ with increasing tungsten content, as observed in Fig. 3, the pore size distribution takes significant change due to the tungsten substitution.

The introduction of tungsten oxide caused the decrease of surface area and the increase of pore volume and pore diameter with increasing tungsten oxide content.

\subsection{HRTEM analysis}

To investigate the pore structure of W-MCM-48, The HRTEM of the prepared samples are obtained and shown in Fig. 4. Electron micrographs have been recorded along direction [111] (the [111] direction image is similar to that reported previously by Monnier et al. [3]). As $\mathrm{Si} / \mathrm{W}$ is 93 and 45 , the order of pore is distinguished well. The ratio of $\mathrm{Si} / \mathrm{W}$ decreases, definition becomes worse. As $\mathrm{Si} / \mathrm{W}$ is 20 , the quality of the images becomes disorderly and unsystematic. The reason results from more tungsten incorporated, the results are in good agreement with the XRD result.

\subsection{UV-Vis DRS}

UV-Visible diffuse reflection spectroscopy is a direct and effective method for determining local molecular

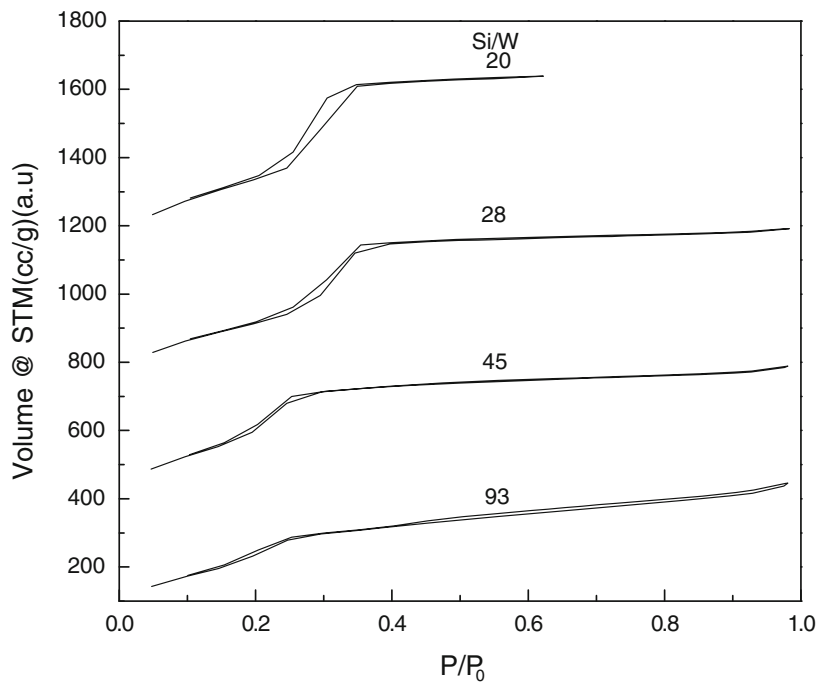

Fig. $3 \mathrm{~N}_{2}$ adsorption/desorption isotherm 
Table 1 Structural parameters of the MCM- 48 with different ratio of $\mathrm{Si} / \mathrm{W}$

\begin{tabular}{|c|c|c|c|c|}
\hline \multirow[t]{3}{*}{ Samples } & \multicolumn{4}{|l|}{ BET } \\
\hline & \multicolumn{2}{|c|}{ Specific surface area } & \multirow{2}{*}{$\begin{array}{l}\text { Pore } \\
\text { volume } \\
\left(\mathrm{cm}^{3} / \mathrm{g}\right)\end{array}$} & \multirow{2}{*}{$\begin{array}{l}\text { Pore } \\
\text { diamete } \\
(\mathrm{nm})\end{array}$} \\
\hline & $\overline{\mathrm{Si} / \mathrm{W}}$ & $\left(\mathrm{m}^{2} / \mathrm{g}\right)$ & & \\
\hline W-MCM-48(93) & 93 & 1,328 & 0.69 & 1.97 \\
\hline W-MCM-48(45) & 45 & 1,264 & 0.75 & 2.21 \\
\hline W-MCM-48(28) & 28 & 1,092 & 0.85 & 2.48 \\
\hline W-MCM-48(20) & 20 & 969 & 1.05 & 2.76 \\
\hline
\end{tabular}

coordination and bonding information for inorganic compounds such as simple mixed oxides [30-35].

To obtain the chemical nature and coordination state of tungsten oxide species, the diffuse reflectance spectra in the UV-Visible region of W-MCM-48 samples with different $\mathrm{Si} / \mathrm{W}$ ratios are recorded and shown in Fig. 5. Diffuse- reflectance UV-Vis spectrum is a sensitive tool that is widely used to detect the presence of framework and extra framework tungsten species [8, 36]. Two characteristic bands have been resolved for W-containing materials in the UV-Vis spectrum; two intense bands are centered at 225 and $270 \mathrm{~nm}$. The band at $225 \mathrm{~nm}$ was attributed to an isolated $\left[\mathrm{WO}_{4}\right]$ tetrahedral species $[37,38]$ depending on the ligand field symmetry surrounding the $\mathrm{W}$ center $[26$, 39], which is generally regarded as the direct proof that transition metal atoms have been incorporated into the framework of a molecular sieve [40]. Therefore, it should be considered as the direct proof for the presence of the framework tungsten species in tetrahedral coordination. The band at $270 \mathrm{~nm}$ may be attributed to a distorted tetrahedral coordination environment or the existence of some tungsten species in an octahedral coordination environment [8]. The intensity of the two bands is found to increase with the increase of tungsten content, which suggests that the amount of framework tungsten oxide species increased.
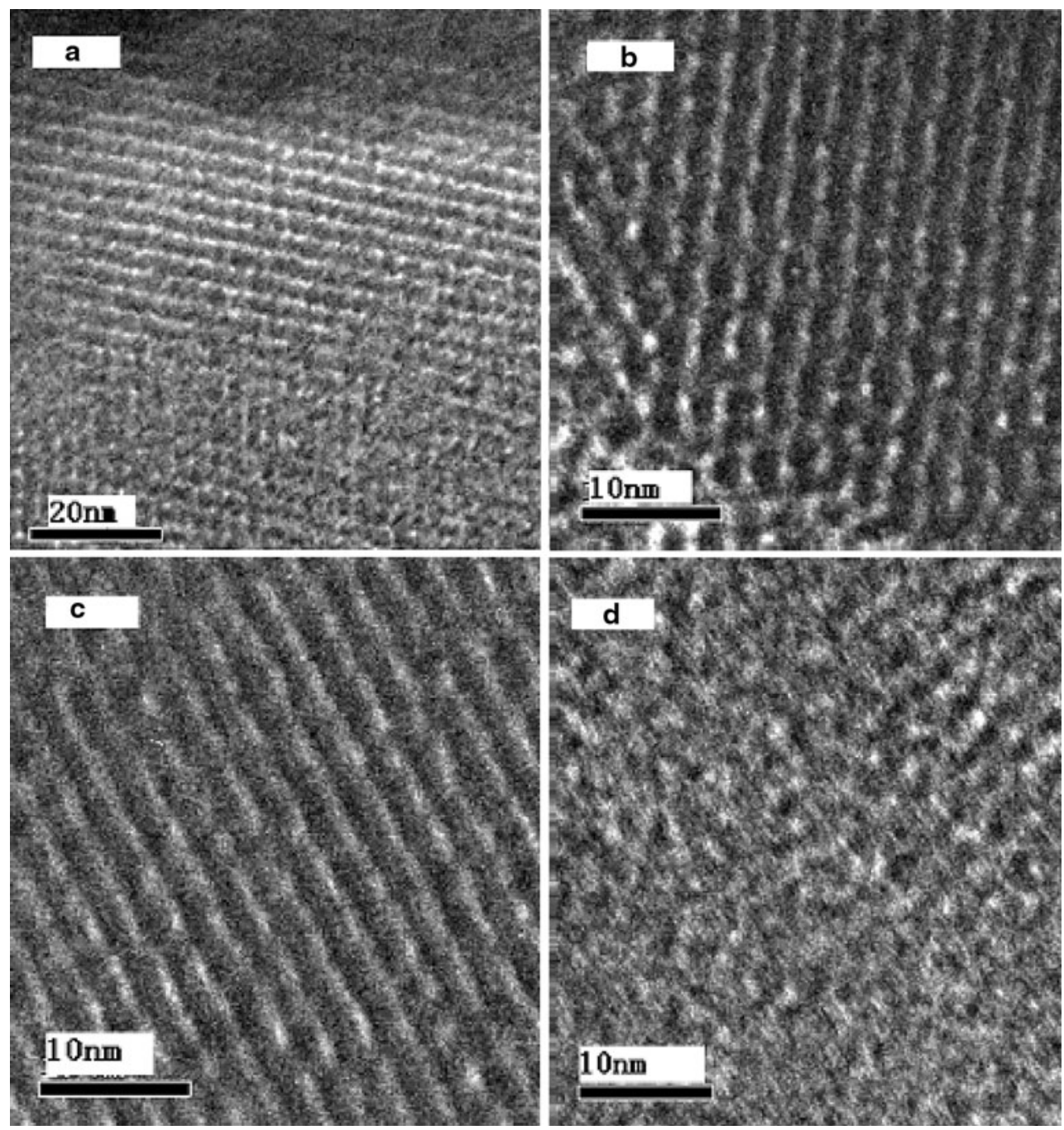

Fig. 4 HRTEM image of W-MCM-48 with different Si/W ratios $(a=93, b=45, c=28, d=20)$ 


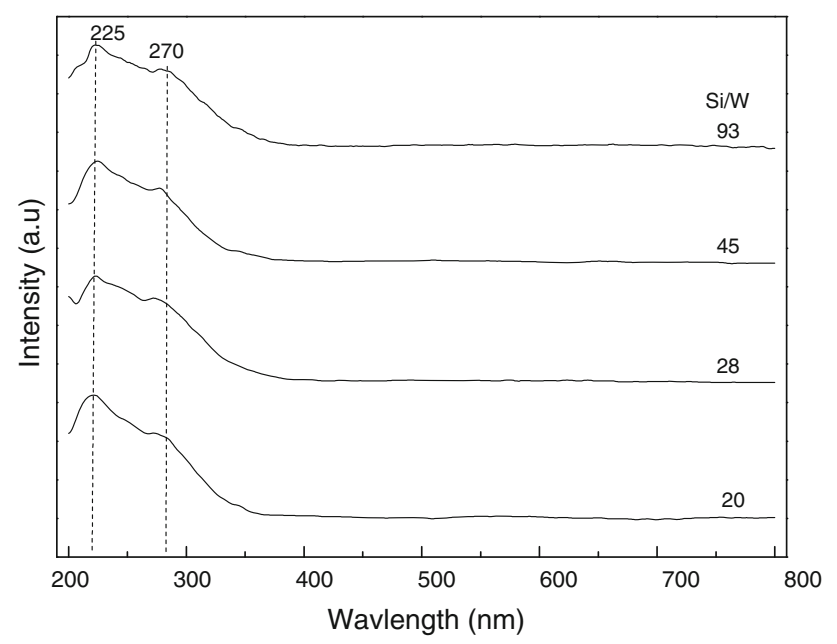

Fig. 5 UV-Vis diffuse reflectance spectra of W-MCM-48

\subsection{FT-IR}

The FT-IR spectra of the W-MCM-48 samples in the region $1,300-400 \mathrm{~cm}^{-1}$ is showed in Fig. 6. All samples exhibite the infrared absorption bands at 460, 560, 800, $880,960,1,086$ and $1,220 \mathrm{~cm}^{-1}$. The IR spectra present a vibration band at $560 \mathrm{~cm}^{-1}$, which is assigned to the asymmetric stretching mode of double five rings in the MFI framework [41, 42]. On the basis of previous literature assignments for silicate materials, the IR spectra for W-MCM-48 samples show characteristics absorption bands at $460,800,1,086$ and $1,220 \mathrm{~cm}^{-1}$ that assigned to symmetric and asymmetric stretching of $\mathrm{Si}-\mathrm{O}-\mathrm{Si}$ vibrations for the tetrahedral $\mathrm{SiO}_{4}$ structure units. These bands are usually assigned to $\delta(\mathrm{Si}-\mathrm{O}-\mathrm{Si}), \mathrm{V}_{\mathrm{s}}(\mathrm{Si}-\mathrm{O}-\mathrm{Si})$ and $\mathrm{V}_{\text {as }}$ ( $\mathrm{Si}-\mathrm{O}-\mathrm{Si}$ ), respectively [43-46]. An absorption band in the $945-980 \mathrm{~cm}^{-1}$ region that characterizes the vibrational

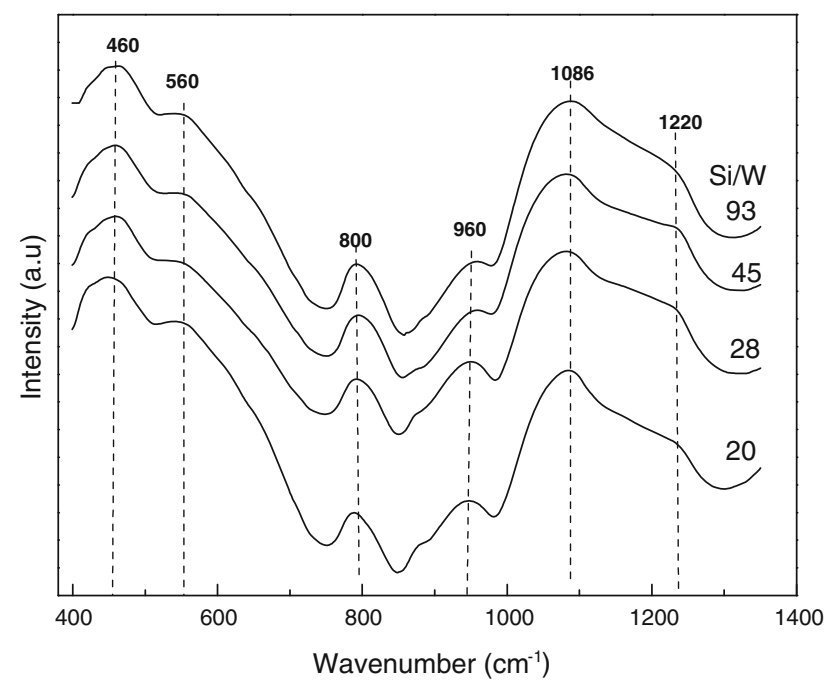

Fig. 6 FT-IR spectra of W-MCM-48 spectrum of transition-metal elements incorporated in silicate may be considered the fingerprint of framework transition-metal [47-49]. Then the vibration at $960 \mathrm{~cm}^{-1}$ may be attributable to the $\mathrm{W}-\mathrm{O}-\mathrm{Si}$ linkage in the W-MCM-48. Furthermore, the intensity of the $960 \mathrm{~cm}^{-1}$ band enhanced with the increase in the tungsten content in the W-MCM-48 samples, which suggest the incorporation of tungsten in the mesoporous matrix.

\section{Conclusions}

In conclusion, the tungsten is effectively introduced into ordered mesoporous MCM-48 in strong akaline medium in a facile way by using CTAB as template by one step. These materials have high srface area $\left(>900 \mathrm{~m}^{2} / \mathrm{g}\right)$, uniform pore channels, the TEM picture allows to estimate the pore size (30). The tungsten species are highly dispersed in the silica-based framework structure. As $\mathrm{Si} / \mathrm{W}>28$, the caracterization results indicate that the framework structure of the synthesized W-MCM-48 is long-range order.

Open Access This article is distributed under the terms of the Creative Commons Attribution Noncommercial License which permits any noncommercial use, distribution, and reproduction in any medium, provided the original author(s) and source are credited.

\section{References}

1. C.T. Kresge, M.E. Leonowicz, W.J. Roth, J.C. Vartuli, J.S. Beck, Nature 359, 710 (1992)

2. A.H. Schoen, NASA Technical note NO TN D-5541 (1970)

3. A. Monnier, F. Schüth, Q. Huo, D. Kumar, D. Margolese, Science 5126, 1299 (1993)

4. V. Alfredsson, M.W. Anderson, Chem. Mater. 8, 1141 (1996)

5. J. Xu, Z. Luan, H. He, W. Zhou, L. Kevan, Chem. Mater. 10, 3690 (1998)

6. Z.R. Zhang, J.S. Suo, X.M. Zhang, S.B. Li, Chem. Mater. 2, 41 (1999)

7. A. Corma, M. Navarro, J. Chem. Commun. 2, 147 (1994)

8. T. Blasco, A. Corma, M.T. Navarro, J. Perez-Pariente, J. Catal. 156, 65 (1995)

9. Y. Yue, A. Gedeon, J.L. Bonardet, N. Melosh, J.B.D. Espinose, J. Fraissard, Chem. Commun. 19, 1967 (1999)

10. W.Zhang, Q. Lu, B. Han, M. Li, J. Xiu, P. Ying, C. Li, Chem. Mater. 14, 3413 (2002)

11. P. Van Der Voort, B. Michael, E.F. Vansant, Catal. Today. 68, 119 (2001)

12. P. Selvam, S.E. Dapurkar, Appl. Catal. A: General. 276, 257 (2004)

13. M. Eswaramoorthy, C.N.R. Rao, Chem. Commun. 5, 615 (1998)

14. T. Vrålstad, G. Øye, J. Sjöblom, M. Stöcker, Microporous and Mesoporous Mater 104, 10 (2007)

15. H. Kosslick, G. Lischke, H. Landmesser, B. Parlitz, W. Storek, R. Fricke, J. Catalysis 176, 102 (1998)

16. R. Schmidt, H. Junggreen, M. Stocker, Chemical Commun. 9, 875 (1996)

17. X.L.Yang, W.L.Dai, H.Chen, J.H.Xu, Y.Cao, H.X.Li, K.N. Fan, Appl. Catal. A: General. 283, 1 (2005) 
18. C.W. Guo, W.L. Dai, Y. Gao, S.H. Xie, K.N. Fan, Acta Chimica Sinica 61, 1496 (2003)

19. J.C. Hu, Y.D. Wang, L.F. Chen, R. Richards, W.M. Yang, Z.C. Liu, W. Xu, Microporou and Mesoporous Mater 93, 158 (2006)

20. W.L. Dai, H. Chen, J.H. Xu, Y. Cao, H.X. Li, K.N. Fan, Chem. Commun. 7, 892 (2003)

21. H. Chen, W.L. Dai, J.F. Deng, K.N. Fan, Catal. Lett. 81, 131 (2002)

22. Z.R. Zhang, J.H. Suo, X.M. Zhang, S.B. Li, Appl. Catal. A: General. 179, 11 (1999)

23. X.L. Yang, W.L. Dai, R.H. Gao, H. Chen, H.X. Li, Y. Cao, K.N. Fan, J. Mol. Catal. A. 241, 205 (2005)

24. Y.J. Zhang, S.L. Zhao, G.D. Sun, Z.L. Wang, Chin. J. Catal. 21, 345 (2000)

25. M.S. Morey, J.D. Bryan, S. Schwarz, G.D. Stucky, Chem. Mater. 12, 203 (2000)

26. J.-C. Hu, Y.-D. Wang, L.-F. Chen, R. Richards, W.-M. Yang, Z.C. Liu, W. Xu, Microporous and Mesoporous Mater 93, 158 (2006)

27. H. Yoshitake, T. Yokoi, T. Tatsumi, Chem. Mater. 15, 1713 (2003)

28. X. Chen, L. Huang, Q. Li, J. Phys. Chem. B. 101, 8460 (1997)

29. W.H. Zhang, J.Q. Lu, B. Han, e.a.M.J. Li, Chem. Mater. 14, 3413 (2002)

30. M.S. Morey, J.D. Bryan, S. Schwarz, G.D. Stucky, Chem. Mater. 12, $3435(2000)$

31. R.K. Rana, B. Viswanathan, Catal. Lett. 52, 25 (1998)

32. U.S.Taralkar, P. Kalita, R. Kumar, P.N. Joshi, Appl. Catal. A: General. 358, 88 (2009)
33. R. Cid, F.J.G. Llambias, A.1. Agudo, J. Villasenor, J. Catal. 89, 478 (1984)

34. Y. Iwasawa, M. Yamagishi, J. Catal. 82, 373 (1983)

35. Y. Wang, Q.H. Zhang, Y. Ohishi, T. Shishido, K. Takehira, Catal. Lett. 72, 3 (2001)

36. J.S. Reddy, A. Sayari, J. Chem. Soc., Chem. Commun. 22, 2231 (1995)

37. E. Briot, J.Y. Piquemat, M. Vennat, J.M. Bregeault, G. Chottard, J.M. Manoli, J. Mater. Chem. 10, 953 (2000)

38. C.W.F.T. Pistorius, J. Chem. Phys. 44, 4532 (1966)

39. G.N. Vayssilov, Catal. Rev-Sci. Eng. 39, 209 (1997)

40. G.N. Vayssilov., Catal. Rev. Sci. Eng. 39, 209 (1997)

41. D.W. Breck, Zeolite Molecular Sieves (Wiley, New, York, 1974)

42. P.A. Jacobs, E.G. Derouane, J. Weitkamp, J. Chem. Soc. Chem. Commun. 12, 591 (1981)

43. M.D. Alba, Z.H. Luan, J. Klinowski, J. Phys. Chem. 100, 2178 (1996)

44. B.L. Newalkar, J. Olanrewaju, S. Komarneni, Chem. Mater. 13, $552(2001)$

45. C.Y. Chen, H.X. Li, M.E. Davis, Microporous Mater. 2, 17 (1993)

46. H.T. Gomes, P. Selvam, S.E. Dapurkar, J.L. Figueiredo, J.L. Faria, Microporous and Mesoporous. Mater. 86, 287 (2005)

47. M.D. Alba, Z. Luan, J. Klinowski, J. Phys. Chem. 100, 2178 (1996)

48. A. Thangaraj, R. Kumar, P. Ratnasamy, Appl. Catal. 57, L-1 (1999)

49. C. Hao, W.L. Dai, J.F. Deng, K.N. Fan., Catal. Lett. 81, 131 (2002) 